\title{
Commentary: Right ventricular--tricuspid valve interdependence and the challenges for structural heart valve therapy
}

\author{
Amedeo Anselmi, MD, PhD
}

\author{
From the Division of Thoracic and Cardiovascular Surgery, Pontchaillou University Hospital, Rennes, France. \\ Disclosures: Author has nothing to disclose with regard to commercial support. \\ Received for publication Dec 30, 2018; accepted for publication Dec 31, 2018; available ahead of print Jan 31, \\ 2019. \\ Address for reprints: Amedeo Anselmi, MD, PhD, Division of Thoracic and Cardiovascular Surgery, Pontchaillou \\ University Hospital, Rennes, France (E-mail: amedeo.anselmi@chu-rennes.fr). \\ J Thorac Cardiovasc Surg 2019;158:769-802 \\ $0022-5223 / \$ 36.00$ \\ Copyright (c) 2019 by The American Association for Thoracic Surgery \\ https://doi.org/10.1016/j.jtcvs.2018.12.094
}

There is accumulating evidence indicating close biomechanical interdependence between the right ventricle (RV) and the tricuspid valve annulus, leaflets, and subvalvular apparatus. The investigation presented in this issue of the Journal by the focused research group of Jazwiec and colleagues ${ }^{1}$ proposes an ovine model of acute right heart failure, with the scope to provide novel insights about pathophysiology and response to treatment. Some obvious limitations need to be underscored. Among these is the acute nature of right-sided heart failure produced in this model, which contrasts with most usual clinical scenarios (chronic volume overload, pulmonary hypertension, RV myocardial failure). These chronic factors may be associated with different RV myocardial material properties with respect to the acute settings, and potentially with different behavior of free wall stress and strain. Another limitation is the lack of evaluation of the interventricular septal function after ligation of the posterior descending artery branch, and the potential influence of septal dysfunction on RV geometric properties. Yet another is the lack of confirmation of these results in human hearts.

Nonetheless, Jazwiec and colleagues ${ }^{1}$ propose innovative insights into the RV-tricuspid valve relationship and raise several points. First, tricuspid annular dilatation seems to follow RV dysfunction immediately, rather than only occurring as the delayed consequence of chronic RV remodeling. Second, correction of annular dilatation affects multiple biomechanical components of the RV pathophysiology, and through such pathways seems to induce favorable RV remodeling independent of the amendment of tricuspid regurgitation itself. Third, continued investigations in this field might help us better to predict the reversibility of RV dysfunction and the risk of severe postoperative RV failure in individual cases. It can be anticipated that structural interventions, not only on the tricuspid annulus but also on leaflets and subvalvular apparatus, entail immediate biomechanical consequences (including modulation of RV wall

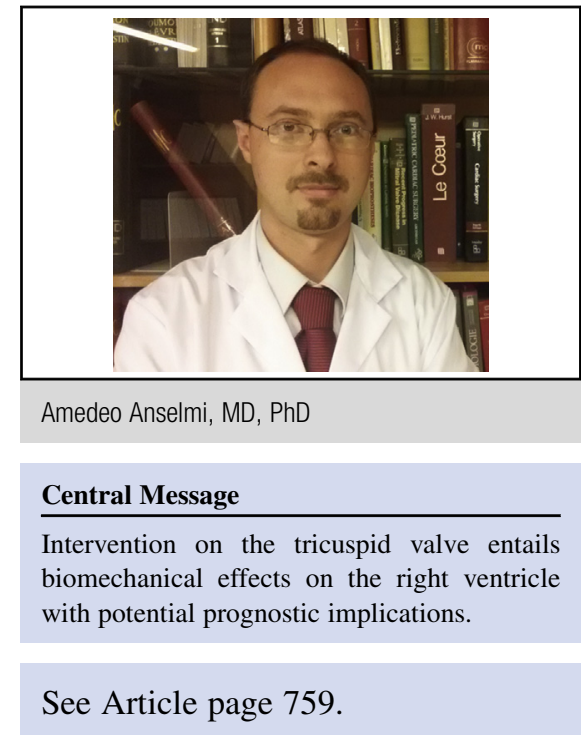

stress and strain), which can discriminate the fate of a failing right ventricle. The implications of such consequences on long-term RV function and reverse remodeling in clinical chronic RV disease are beyond the scope of this article but probably represent the major issue provoked by Jazwiec and colleagues. ${ }^{1}$

In this context, the clinician should not limit focus to correction of tricuspid regurgitation alone but should also aim at durable results concerning RV function. If the current results are confirmed in human hearts, modulation of RV biomechanical behavior (ie, reduction of wall stress and strain) and facilitation of reverse remodeling can be pivotal in such perspective. The study of Jazwiec and colleagues ${ }^{1}$ suggests that any intervention we perform over the tricuspid valve is likely to affect the function of the RV itself in the midterm to long term and therefore heavily condition the patient's prognosis. The largest clinical registry to date of multiple $(\mathrm{N}=6)$ innovative strategies for the treatment of tricuspid regurgitation presents only 6-day follow-up. ${ }^{2}$ It also underscores unchanged RV dysfunction despite improvement of tricuspid regurgitation grade. The RVtricuspid valve pathophysiologic interaction may prove delicate to interpret and treat for any interventional strategy unable to release the RV biomechanical stress coupled with tricuspid annular dilatation. Here lies one gap to be filled by tricuspid percutaneous device concepts; simple correction 
of tricuspid regurgitation may not be enough for their clinical success if other elements of tricuspid valve-RV interdependence are not properly addressed (ie, through adequate management of the annulus).

Similarly, there is increasing interest in midterm and long-term evaluations of transcatheter aortic valve replacement, not only with respect to the profile of device function but also to that of global cardiac function (ie, late prognostic impact of left bundle branch block and permanent pacemaker on reverse left ventricular remodeling and wall biomechanical properties). ${ }^{3,4}$

\section{References}

1. Jazwiec T, Malinowski M, Bush J, Goehler M, Quay N, Parker J, et al. Right ventricular free wall stress after tricuspid valve annuloplasty in acute ovine right heart failure. J Thorac Cardiovasc Surg. 2019;158:759-68.

2. Taramasso M, Hahn R, Alessandrini H, Latib A, Attinger-Toller A, Braun D, et al. The International Multicenter TriValve Registry. JACC Interv. 2017;10: 1982-90.

3. Dizon JM, Nazif TM, Hess PL, Biviano A, Garan H, Douglas PS, et al. PARTNER Publications Office. Chronic pacing and adverse outcomes after transcatheter aortic valve implantation. Heart. 2015;101:1665-71.

4. Dobson LE, Musa TA, Uddin A, Fairbairn TA, Bebb OJ, Swoboda PP, et al. The impact of trans-catheter aortic valve replacement induced left-bundle branch block on cardiac reverse remodeling. J Cardiovasc Magn Reson. 2017;19:22. 